\title{
Zur Paläo-Geoökologie der Zentralen Anden - Einführung zum Themenheft
}

\section{Heinz Veit, Bern}

Die Zentralen Anden in Nordchile, Nordwestargentinien und Boliven zählen zu den trockensten Gebirgen der Erde. Dieser Andenabschnitt ist Teil eines riesigen Trockengebietes, das von Nordperu bis an die patagonische Atlantikküste reicht und als «Aride Diagonale» Südamerikas bezeichnet wird. Der diagonale Verlauf erklärt sich durch die Lage im Übergangsbereich unterschiedlicher atmosphärischer Zirkulationssysteme. Im Norden bringen tropische Ostwinde im Sommer zwar Feuchtigkeit aus dem Amazonasgebiet bis auf den Altiplano («Invierno Boliviano»), erreichen aber die tieferen Lagen der Atacama auf der Leeseite nicht. Im Süden sind die Westwinde verantwortlich für die hohen Niederschläge im chilenischen Seengebiet. Dort liegt die argentinische Pampa im Windschatten. In den Anden befindet sich der trockenste Abschnitt etwa bei $24-26^{\circ} \mathrm{S}$, wo die Aride Diagonale die Anden quert (Abb. 1).

Trotz der heutigen Trockenheit finden sich deutliche Spuren feuchterer Perioden der Vergangenheit. Moränen dokumentieren die Existenz von ehemals kilometerlangen Gletschern in dieser Hochgebirgswüste, limnische Sedimente belegen um Dekameter höhere Seespiegel der Salare, mit einer Vervielfachung der Seefläche auf dem Altiplano. Bodenbildungen weisen auf eine geschlossene Vegetationsdecke hin. Die Verhältnisse von «trocken» und «feucht» haben in der Vergangenheit mehrfach gewechselt. In dieser heute so erstarrt und regungslos erscheinenden Landschaft steckt demnach eine ungeheuere Dynamik, deren Auslöser klimatische Veränderungen waren. Einen Überblick über die paläo-geoökologische Entwicklung der Zentralen Anden und darüber hinaus in Südamerika geben die Arbeiten von Clapperton (1993), Veit (2000), Veit \& Grosjean (2003), Latorre et al. (im Druck) und VeIT (2006).

Die trockenen Zentralen Anden sind äusserst sensitiv gegenüber Klimaschwankungen, vor allem gegenüber Änderungen im Wasserhaushalt. Deshalb liefern sie über die regionale Erforschung der Landschaftsgeschichte hinaus Informationen über Änderungen der südhemisphärischen atmosphärischen Zirkulation. Wenn sich die Herkunft der niederschlagsbringenden Luftmassen für die verschiedenen Perioden der Vergangenheit rekonstruieren lässt, erhält man Hinweise z.B. auf zeitweise verstärkten Westwindeinfluss, auf eine Intensivierung der tropisch monsunalen Strömung und - bei langen Zeitreihen - auf mögliche steuernde
Elemente, wie z.B. die Erdbahnparameter (Milankovitch-Zyklen) mit ihrem ca. 20 ka- (Präzession), 40 ka(Obliquität) oder 100 ka-Rhythmus (Exzentrizität). Damit stehen die Untersuchungen letztlich in einem südhemisphärischen bis globalen Zusammenhang.

Die Klimageschichte der Zentralen Anden wird seit Jahrzehnten sehr kontrovers diskutiert. Die verschiedenen Befunde widersprechen sich teilweise oder werden unterschiedlich interpretiert. Dies war für die Arbeitsgruppe «Paläo-Geoökologie» am Geographischen Institut der Universität Bern vor fast zwanzig Jahren der Grund, an dieser paläoklimatischen Schlüsselstelle Südamerikas, im Übergangsbereich von tropischer und ektropischer atmosphärischer Zirkulation, mit Forschungen zu beginnen. Im vorliegenden Heft der Geographica Helvetica werden einige neuere Arbeiten zu diesem Thema vorgestellt.

Die Beiträge von ZeCH et al., ImHof et al. und SCHeLLENBERGER (Abb. 1: 1,2,3) erläutern die wechselvolle Landschafts- und Klimageschichte der Zentralen Anden anhand von Gletscherschwankungen und Paläoboden-Löss-Sequenzen. Die beiden Beiträge über die jungquartären Gletschervorstösse stellen methodisch innovative Ansätze vor. ZECH et al. ermöglichen mit der kritischen Anwendung der ${ }^{10} \mathrm{Be}$-Datierungen von Moränenblöcken erstmals eine genauere zeitliche Einordnung der zentralandinen Gletscherhochstände. Aufgrund der grossen Trockenheit und entsprechendem Mangel an organischem Material für die ${ }^{14} \mathrm{C}$-Datierung gab es hierzu bislang keine genauen Informationen, nur Vermutungen. IMHOF et al. entwikkeln ein Modell, mit dem sich die klimatischen Bedingungen, die zu den ausgedehnten Gletschervorstössen geführt hatten, quantitativ rekonstruieren lassen. Beide Arbeiten zusammen zeigen ein neuartiges Bild der Gletscher- und Klimageschichte der letzten 30.000 Jahre.

In den argentinischen Anden liegen im Becken von Tafí in Nordwestargentinien mächtige Lössablagerungen, die durch eingeschaltete Verwitterungshorizonte ein einmaliges Langfrist-Klimaarchiv für Südamerika südlich des Äquators darstellen. In den mehr als $50 \mathrm{~m}$ mächtigen äolischen Sedimenten belegen 32 fossile Böden eine zyklische Klimaentwicklung mit grossen Variationen der Umweltbedingungen seit mehr als 1,2 Mio. Jahren. Trockene Phasen mit Deflation im argentinischen Tiefland (Chaco, Pampa) und simultaner Lössakkumulation in dem als Sedimentfalle fungierenden Becken wechselten mit feuchteren Bodenbildungsphasen $\mathrm{ab}$. 


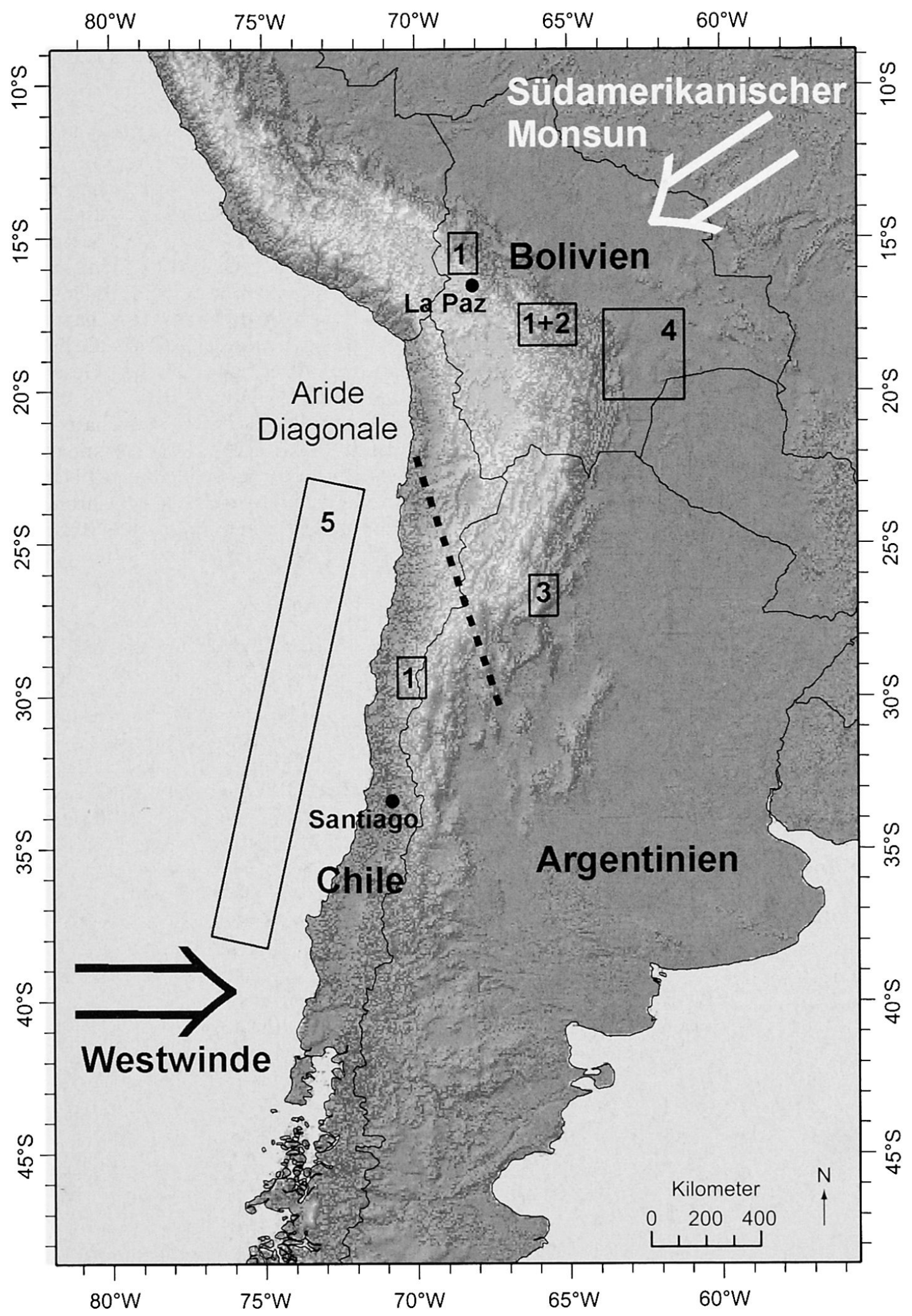

Abb. 1: Lage der in diesem Heft vorgestellten Untersuchungsgebiete (1 = ZECH et al., 2 = IMHOF et al., 3 = SCHELLENBERGER, 4 = MAY, 5 = STUUT et al.)

Locations of the research areas presented in this issue

Localisation des zones de recherche présentées dans ce cahier

Kartengrundlage: Gtopo30, Digitales Höhenmodell 
Die klimatischen Veränderungen in den Hochlagen der Zentralen Anden hatten Auswirkungen bis in die tief gelegenen Vorländer. Im Beitrag von MAY (Abb. 1: 4) wird die Entwicklung des bolivianischen Andenvorlandes beleuchtet. Hier ist der Kenntnisstand von allen vorgestellten Gebieten bislang am geringsten. Die geomorphologische Grobgliederung und die Ausgliederung verschiedener Landschaftseinheiten mit modernen Fernerkundungs- und Feldmethoden liefern ein erstes grundlegendes Gerüst zum Verständnis der quartären Entwicklung Ostboliviens. Auf der Westseite der Anden ist der Zusammenhang Hochland - Tiefland hervorragend in marinen Sedimenten dokumentiert. Zahlreiche Bohrungen vor der chilenischen Küste belegen mit hoher zeitlicher Auflösung die enge Verknüpfung terrestrischer und mariner Prozesse. Stuut et al. (Abb. 1:5) geben einen guten Überblick über die Arbeiten ihrer Forschungsgruppe während der letzten Jahre und präsentieren wesentliche Ergebnisse zur Geschichte der südhemisphärischen Westwindzone.

\section{Dank}

Für die finanzielle Unterstützung an die Drucklegung des vorliegenden Heftes sei der Stiftung Marchese Francesco Medici del Vascello gedankt.

\section{Literatur}

Clapperton, C. (1993): Quaternary geology and geomorphology of South America. - Amsterdam: Elsevier.
Latorre, C., Moreno, P.I., Vargas, G., Maldonado, A., Villa-Martínez, R., Armesto, J.J., Villagrán, C., Pino, M., Nuñez, L. \& M. Grosjean: Quaternary environments and landscape evolution. - In: GibBons, W. \& T. Moreno (Hrsg.): The geology of Chile. - London: Geological Society Press (im Druck).

Verr, H. (2000): Klima- und Landschaftswandel in der Atacama. - In: Geographische Rundschau 52, 9: 4-9.

Veit, H. \& M. Grosjean (2003): Seespiegelschwankungen und Paläoböden als Zeugnisse langfristiger Klimaveränderungen in den Zentralen Anden. - In: Jeanneret, F., Wastl-Walter, D., Wiesmann, U. \& M. SCHWYN (Hrsg.): Welt der Alpen - Gebirge der Welt. - = Jahrbuch der Geographischen Gesellschaft Bern 61, Bern; Haupt Verlag: 31-36.

VeIT, H. (2006): Quartäre Landschafts- und Klimageschichte Südamerikas. - In: Borsdorf, A. (Hrsg.): Grüne Hölle oder buntes Paradies? Naturräumliche Grundlangen Lateinamerikas. - = Jahrbuch des Österreichischen Lateinamerika-Instituts 10: 53-74.
Prof. Dr. Heinz Veit, Geographisches Institut, Universität Bern, Hallerstrasse 12, CH-3012 Bern, Schweiz. e-mail:veit@giub.unibe.ch 